\title{
The effect of three months of aerobic training on response preparation in older adults
}

\author{
Mélanie Renaud ${ }^{1,2}$, François Maquestiaux ${ }^{3}$, Steve Joncas ${ }^{4}$, Marie-Jeanne Kergoat ${ }^{2}$ and Louis Bherer ${ }^{1,2 *}$ \\ 1 Department of Psychology, University of Québec at Montréal, Montréal, QC, Canada \\ Centre de Recherche, Institut Universitaire de Gériatrie de Montréal, Montréal, QC, Canada \\ ${ }^{3}$ Unité de Recherche Complexité, Innovation, Activités Motrices et Sportives, Université Paris-Sud 11, Paris, France \\ ${ }^{4}$ Bruyere Continuing Care, Ottawa, ON, Canada
}

Edited by:

Lars Nyberg, Umeå University,

Sweden

\section{Reviewed by:}

Kirk I. Erickson, University of Illinois at Urbana-Champaign, USA

Anna Sundström, Umeå University,

Sweden

\section{*Correspondence:}

Louis Bherer, Département de

psychologie, Université du Québec à

Montréal, C.P. 8888 Succursale

Centre-ville, Montréal, QC, Canada

H3C $3 \mathrm{P} 8$.

e-mail: bherer.louis@uqam.ca
This study assessed the effects of an aerobic training program on reaction time tasks that manipulated preparatory intervals (PI) to produce temporal preparation effects using short $(1,3,5 \mathrm{~s})$ and long $(5,7,9 \mathrm{~s}) \mathrm{PI}$. Older adults were assigned to either a 3-month aerobic training group or to a control group. Individuals in the training group participated in an aerobic training program of three 60-min sessions per week. The control group did not receive any training. Results indicated that 12 weeks of aerobic training induced a significant improvement in cardiorespiratory capacity $\left(\mathrm{VO}_{2}\right.$ max estimate). All participants who completed the aerobic program showed improvement after training in the choice RT task, along with enhanced preparation, such that they maintained preparation over time more efficiently after the training program. Moreover, enhanced ability to use the short PI was observed but only in lower fit individuals. Results of the present study suggest that improving aerobic fitness may enhance attentional control mechanisms in older adults.

Keywords: aging, aerobic training, task complexity, response preparation

\section{INTRODUCTION}

Aging is accompanied by important changes in the central nervous system, which can lead to cognitive declines. In fact, substantial anatomical and physiological modifications have been observed in the frontal areas of the cerebral cortex in the aging brain (West, 1996; Raz, 2000), and this has been associated with declines in attentional control (for a review, see McDowd and Shaw, 2000). The ability to prepare a speeded response, and to maintain this preparation over time, is an attentional control process that has been found to decline with age in some conditions (Salthouse, 1985; Bherer and Belleville, 2004a,b). However, recent studies have shown that age-related cognitive decline is heterogeneous among older individuals and that lifestyle factors, such as physical exercise, can modulate the impact of aging on cognition (Kramer et al., 2004; Hertzog et al., 2009). The present study assessed whether a physical exercise program can lead to significant changes in attentional control mechanisms that support response preparation.

Cross-sectional studies have suggested that physical activity can be an important moderator of age-related cognitive decline. For instance, Spirduso (1975) observed that older racquet and handball players were faster in both simple and choice reaction time (RT) tasks compared to age-matched non-players. Clarkson-Smith and Hartley (1989) also observed faster RTs in physically active elderly participants than in sedentary older adults (for similar results in women aged over 60, see Abourezk and Toole, 1995).

Further evidence for the moderating effect of physical activity on age-related cognitive declines stems from intervention studies. Dustman et al. (1984) compared middle age and older individuals that completed a 4-month training program to an age-matched control group that engaged in strength and flexibility exercises, and a control group that did not exercise. Improvements in cardiorespiratory function were found in the training group only, along with improvements in a simple RT task. Similar results were obtained in women aged 57-85 years old, following a 3-year physical training program (Rikli and Edwards, 1991). Hawkins et al. (1992) reported that, in older adults, a 10-week aquatic fitness program, led to larger improvement in tasks conditions that tap dual-task and switching abilities compared to conditions that do not require executive or attentional control processes. Kramer et al. (1999) also observed that after a 6-month walking program, participants (aged 65-70 years old) showed significant improvement in task conditions that required executive or controlled functions. These findings have been further supported in a recent meta-analysis on 18 intervention studies with participants aged 60 years and older (see Colcombe and Kramer, 2003; but see Etnier et al., 2006 for different conclusions).

Most of the studies reported previously suggest that in older adults, enhancing aerobic fitness leads to significant improvement in attentional control functions. However, some of them that used RT paradigms, reported equivalent improvement after training, in both simple and choice RT tasks. This observation is at odds with the assumption that fitness training has a larger impact on the controlled aspect of cognition, which should lead to larger training effects on choice compared to simple RT tasks (Hall et al., 2001). Surprisingly, few studies have directly compared improvement in simple and choice RT tasks after aerobic fitness training. Moreover, RT tasks often vary among studies in term of decision complexity and the ability to predict the moment at which a stimulus will occur. Indeed, RT tasks may engage controlled aspects of attention before the stimulus occurrence if anticipation or response preparation can take place (Niemi and Näätänen, 1981). 
Preparatory processes are a voluntary or attention-demanding set of strategic behaviors that support an optimal processing state prior to the execution of movement (Stuss et al., 1995). In a crosssectional study, Hillman et al. (2002) observed reduced amplitude of the contingent negative variation (CNV), an electrophysiological marker of response preparation, in young and old physically fit participants compared to sedentary individuals. The authors argued that older adults with better aerobic fitness level engaged less cognitive resources than sedentary individuals to prepare a speeded response. In a more recent study, Renaud et al. (2010) observed better response preparation in high fit compared to low fit older adults, particularly when response preparation needed to be maintained over several seconds. Together, these cross-sectional studies suggest that cardiorespiratory fitness is associated with more efficient response preparation processes. However, to date, no intervention study has supported this observation, which limits our understanding of how improved cardiovascular fitness influences response preparation processes.

The aim of the present study was to investigate whether sedentary older adults who participate in an aerobic fitness training program would demonstrate enhanced performances in a simple and a choice RT task. The temporal parameters of the RT tasks were varied to generate specific preparatory effects that have been shown to be affected in normal aging (Salthouse, 1985; Bherer and Belleville, 2004a,b). Moreover, based on findings from a recent study (Renaud et al., 2010) that showed that a high level of cardiorespiratory fitness was associated with better response preparation, another goal of the present study was to assess the effect of baseline physical fitness level on the impact of aerobic training on response preparation. In addition, the tasks used in the present study also provide a measure of both initiation and execution times. These measures allow for the distinction between improvements in attentional control processes involved in response preparation and improvements in motor speed.

\section{MATERIALS AND METHODS PARTICIPANTS}

Prior to acceptance in the study, all the participants completed a telephone interview evaluating their physical health. Participants also completed the modified Questionnaire of aptitude to physical activity (QAA-P), a screening instrument used to detect individuals who may be at risk if they engage in intense physical activity, and the Modifiable Activity Questionnaire (MAQ; Vuillemin et al., 2000) to evaluate their level of physical activity over the 12 past months. All participants met the criteria of sedentary older adults, as they engaged in physical activity less than two times a week.

Participants were excluded if they reported: a history of neurological disease or major surgery in the year preceding the study; auditory or visual impairments that have not been corrected; cardiovascular disease or vascular peripheral attacks, and/or moderate to severe hypertension. To exclude individuals with dementia or depression, participants completed the Mini-Mental State Examination (MMSE, Folstein et al., 1975, cut-off score of 26/30), and the Geriatric Depression Scale (GDS) (Yesavage et al., 1983, cut-off score of 11). General verbal and mental abilities were also assessed (Similarities subtest of the WAIS-III, Wechsler, 1997).
Seventy-seven older adults were recruited through advertizing announcements and posters in community centers in the Montreal area. Ten participants did not meet the inclusion criteria. Of the remaining 67, 32 participants were assigned to the experimental group and 35 were assigned to the control group that did not receive any intervention. Assignment was based on the order of recruitment in the study and on participants' willingness to engage in a 3-month fitness training program. Seventeen individuals ( 7 assigned to the training group and 10 to the control) decided not to engage in the study for personal reasons after completing the pre-test session. In the training group, there was no difference in baseline characteristics between the seven individuals who discontinued and those who remained in the study (see Table 1). In the control group, those who discontinued were older $(p<0.05)$ and had lower scores $(p<0.05)$ on the Similarities subtest of the WAIS-III than those who participated. All the individuals that accepted to participate completed the entire study. In the training group, percentage of attendance to the training sessions was $86.58 \%$. The training group was composed of 21 women and 4 men with a mean age of 67.80 years $(\mathrm{SD}=6.60)$ and 14.36 years $(\mathrm{SD}=4.17)$ of formal education. The control group was also composed of 21 women and 4 men, with a mean age of 67.72 years $(S D=6.01)$ and 12.92 years $(S D=2.61)$ of formal education. The groups were equivalent on a five-point health-rating scale $(5=$ excellent). Training and control participants mean ratings were $4.21(\mathrm{SD}=0.74)$ and $4.17(\mathrm{SD}=0.72)$ respectively.

\section{PROCEDURE}

In a first testing session, participants signed a consent form and completed all screening tests and questionnaires. In a second session all participants completed the simple and the choice RT tasks, followed by a test of cardiorespiratory fitness (Rockport one-mile test; Kline et al., 1987). After these pre-tests, the training group participated in a 12-week aerobic fitness program. After the 12-week period, both the training and the control groups completed a post-test session that included the simple and choice RT tasks and the cardiorespiratory fitness walking test. The study was completed within a 14-week period (1 week of pre-testing, 12 weeks of training, 1 week of post-testing).

\section{AEROBIC FITNESS PROGRAM}

Training group participants engaged in a 3-month physical exercise program with three, $1 \mathrm{~h}$ training sessions per week. During each training session, participants performed different physical activity routines that involved stretching and cardiorespiratory exercises (fast walking and aerobic dancing). Participants did not have a choice in the activities they were enroled in. Basic principles and guidelines for exercise programming (Nelson et al., 2007) were followed, including adequate warm-up and cool-down periods, progressive and gradual increments in exercise duration and energy expenditure. Duration of cardiorespiratory exercise was also gradually increased during the training program, beginning at 15 min per session and increasing until participants were exercising for $40 \mathrm{~min}$ per session. The training sessions were conducted by two professional kinesiologists.

\section{PRE- AND POST-TEST MEASURES}

\section{Cardiorespiratory fitness assessment}

The Rockport one-mile test (Kline et al., 1987) was used to assess cardiorespiratory fitness. This walking test provides an accurate estimate of the maximum level of oxygen consumption 
Table 1 | Participants' baseline characteristics as a function of baseline fitness level.

\begin{tabular}{|c|c|c|c|c|}
\hline & \multicolumn{2}{|c|}{ Control group } & \multicolumn{2}{|c|}{ Training group } \\
\hline & $\begin{array}{l}\text { Lower fit } \\
M(\mathrm{SD})\end{array}$ & $\begin{array}{l}\text { Higher fit } \\
M(\mathrm{SD})\end{array}$ & $\begin{array}{l}\text { Lower fit } \\
M(\mathrm{SD})\end{array}$ & $\begin{array}{l}\text { Higher fit } \\
M(\mathrm{SD})\end{array}$ \\
\hline \multicolumn{5}{|c|}{ GENERAL CHARACTERISTICS } \\
\hline Age & $70.00(6.09)$ & $64.82(4.69)$ & $72.82(5.56)$ & $63.86(4.31)^{*}$ \\
\hline \multicolumn{5}{|c|}{ GENERAL MENTAL ABILITY } \\
\hline MMSE & $29.43(1.02)$ & $28.82(1.25)$ & $28.64(1.12)$ & $28.64(1.08)$ \\
\hline \multicolumn{5}{|c|}{ VERBAL INTELLIGENCE } \\
\hline Similarities & 23.50 (3.98) & $22.45(5.03)$ & $22.36(5.99)$ & $23.21(4.17)$ \\
\hline \multicolumn{5}{|c|}{ MOOD ASSESSMENT } \\
\hline GDS & $5.29(3.41)$ & $5.55(5.36)$ & $3.64(1.43)$ & $5.33(3.41)$ \\
\hline \multicolumn{5}{|c|}{ FITNESS ASSESSMENT } \\
\hline
\end{tabular}

${ }^{*}$ Age difference between the two groups that differed on baseline fitness level $p<0.001$.

$\left(\mathrm{VO}_{2} \mathrm{max}\right)$. Kline et al. (1987) have reported a strong correlation coefficient $(r=0.88)$ between the Rockport estimated $\mathrm{VO}_{2} \max$ and a direct measure of $\mathrm{VO}_{2}$ max during an increment test on a treadmill. For the Rockport one-mile test, participants were instructed to walk one mile without stopping, as fast as possible. They were equipped with a Polar S120 Heart rate Monitor (Polar Electro, Lake Success, NY, USA). The time required to complete the distance was manually recorded on a stopwatch. Heart rate frequency was recorded $1 \mathrm{~min}$ after the end of the walking test. $\mathrm{VO}_{2}$ max was estimated using the equation provided by Kline et al. (1987) ${ }^{1}$ that takes into account participants' weight, age, sex, cardiac frequency post-exercise, and time taken to cover the one-mile distance.

\section{Simple and choice $R T$ tasks}

Response preparation was assessed with a RT paradigm that has shown age-related differences in response preparation (Bherer and Belleville, 2004a,b). To begin each simple and choice RT trial participants pressed a central button on a response box with the index finger. During each trial, they had to keep the home key depressed until the response signal occurred. An auditory signal occurring at the beginning of the trial served as a preparatory signal. The response signal was a black circle appearing in the center of the screen (simple RT) or either on the right or the left side of a white circle located in the center of the screen (choice RT; see Figure 1). In the simple RT task, the participant had to press the response key located on the right side of the home key with the index finger. In the choice RT task, the response button corresponded to the position of the black circle (left or right). In both, the choice and the simple RT tasks, temporal preparation was assessed using preparatory intervals (PI) embedded in a short (PI of 1, 3, 5 s) and a long

${ }^{1}$ Kline et al. (1987) provided two equations to estimate $\mathrm{VO}_{2} \max$ based on the performances obtained at the Rockport one-mile test. Equation 1 provides $\mathrm{VO}_{2}$ max estimate expressed in $1 \mathrm{~min}^{-1}$ and Eq. 2 a $\mathrm{VO}_{2}$ max estimate expressed in $\mathrm{ml} \mathrm{kg}^{-1} \mathrm{~min}^{-1}$. The second equation was used in the present study. Equation $2: \mathrm{VO}_{2} \max =132.853-(0.0769 \times$ weight $)-(0.3877 \times$ age $)+(6.3150 \times$ gender $)-(3.2649 \times$ time $)-(0.1565 \times$ heart rate $), r=0.88, \mathrm{SEE}=5.0 \mathrm{ml} \mathrm{kg} \mathrm{min}^{-1}$.

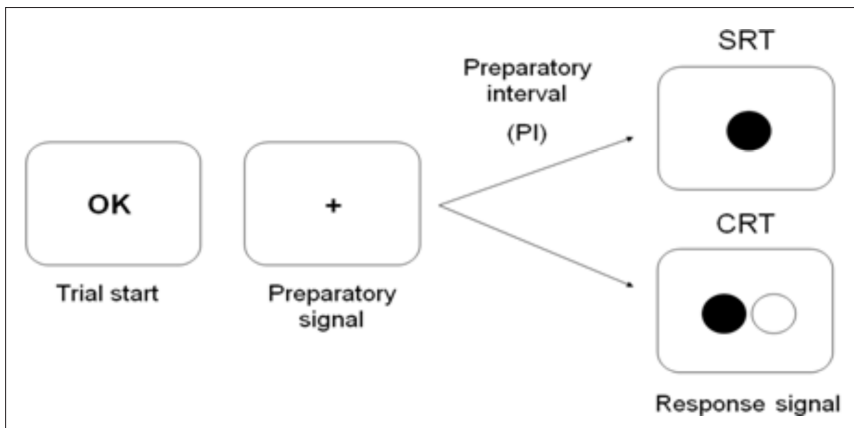

FIGURE 1 | Figural description of the response preparation task.

(PI of 5, 7, 9 s) temporal window. In each window, the three PIs varied randomly and unexpectedly between trials. This procedure produces preparatory functions according to which response time decreases as the PI increases. Thus, as the probability of the response stimulus increases there is increased response preparation. In fact, if three PIs are used randomly, the probability that a response must be provided at the 1 st PI is 0.33 . If nothing occurs at the 1 st PI, probability increases to 0.50 at the 2 nd PI. If no signal occurs at the 2nd PI, the probability that it will occur at the 3rd PI is 1 .

The presentation order of the long and short duration conditions was counterbalanced across participants. Participants were asked to respond as quickly and accurately as possible to each trial. Dependent variables were initiation time (IT), which corresponds to the latency elapsed between the response signal and the release of the home key, and execution time (ET), measured by the time to move from the home key to the response key. Error rates were also recorded.

\section{RESULTS}

To assess the effect of baseline fitness level on training outcomes, all participants were categorized as higher or lower fit individuals based on a median split using the estimated $\mathrm{VO}_{2} \max$ score at baseline. The overall group median at baseline $\left(18.95 \mathrm{ml} \mathrm{kg}^{-1} \mathrm{~min}^{-1}\right)$ 
was used to ensure that the median was not affected by the assignment procedure. Twenty-five participants were part of the lower fit group with a mean $\mathrm{VO}_{2}$ max estimate of $12.94 \mathrm{ml} \mathrm{kg}^{-1} \mathrm{~min}^{-1}$ $(\mathrm{SD}=6.18)$. The higher fit group was also composed of 25 participants with a mean $\mathrm{VO}_{2}$ max estimate of $25.67 \mathrm{ml} \mathrm{kg}^{-1} \mathrm{~min}^{-1}$ $(\mathrm{SD}=6.54)$. In the training group 11 participants were qualified as lower fit, with a mean $\mathrm{VO}_{2}$ max estimate of $10.20 \mathrm{ml} \mathrm{kg} \mathrm{min}^{-1}$ $(\mathrm{SD}=7.82)$ and 14 participants as higher fit, with a mean $\mathrm{VO}_{2}$ max estimate of $25.23 \mathrm{ml} \mathrm{kg}^{-1} \mathrm{~min}^{-1}(\mathrm{SD}=7.72)$. In the control group, 14 participants were qualified as lower fit with a mean $\mathrm{VO}_{2} \max$ estimate of $15.10 \mathrm{ml} \mathrm{kg}^{-1} \mathrm{~min}^{-1}(\mathrm{SD}=3.48)$, and 11 participants as higher fit, with a mean $\mathrm{VO}_{2}$ max estimate of $26.23 \mathrm{ml} \mathrm{kg}^{-1} \mathrm{~min}^{-1}$ $(\mathrm{SD}=4.94)$.

\section{PARTICIPANT'S BASELINE CHARACTERISTICS}

Participant's baseline characteristics as a function of baseline fitness level are presented in Table 1. ANOVAs were performed on the dependent variable of each test with group (training and control) and baseline fitness level (lower and higher) as betweensubjects factors. Results showed no significant difference or interaction between groups and baseline fitness levels on level of formal education, $F(1,46)<1$, MMSE, $F(1,46)<1$, general verbal ability (score on the Similarities subtest of the WAIS-III), $F(1,46)<1$, and score on the GDS, $F(1,46)<1$. Training and control groups were comparable for age, $F(1,46)<1$. However, a significant age difference was observed between the two groups that differed on baseline fitness level, $F(1,46)=22.62, p<0.001$, $\eta^{2}=0.33$. Individuals in the higher fit group were significantly younger $(M=64.28$ years $)$ than individuals in the lower fit group $(M=71.24$ years). Importantly, this age difference was independent of the experimental group factor as indicated by the absence of a three-way interaction of group $\times$ baseline fitness level $\times$ age, $F(1,46)=1.62$, ns. Nevertheless, given the significant age difference in baseline fitness level, the results of this study are reported significant if they remained significant after controlling for age (using age as a covariate in an ANCOVA). Finally, scores on the MAQ indicated that the groups had equivalent amounts of physical activity over the last 12 months $F(1,46)=1.86$, ns.

\section{CARDIORESPIRATORY FITNESS ASSESSMENT}

Analyses performed on the $\mathrm{VO}_{2}$ max estimate showed a main effect of baseline fitness level, $F(1,46)=30.92, p<0.001, \eta^{2}=0.40$, and a significant baseline fitness level $\times$ time interaction, $F(1,46)=5.32, p<0.05, \eta^{2}=0.10$, as the $\mathrm{VO}_{2}$ max estimate improved to a greater extent in the lower fit group, $F(1,24)=14.36, p<0.001$, $\eta^{2}=0.37$, compared to the higher fit group, $F(1,24)=5.71$, $\left.p<0.05, \eta^{2}=0.19\right)$. Of major interest for the present study, a significant group $\times$ time interaction (see Figure $2 \mathrm{~A}$ ) was found, $F(1,46)=25.43, p<0.001, \eta^{2}=0.36$, which confirmed that the participants in the training group showed significant improvement in the $\mathrm{VO}_{2}$ max estimate after 3 months of physical fitness training, $F(1,24)=43.29, p<0.001, \eta^{2}=0.64$, while the $\mathrm{VO}_{2}$ max of control participants remained unchanged, $F(1,24)<1$. The analysis of walking time also confirmed the benefits of the aerobic fitness intervention, as evidenced by a main effect of baseline fitness level, $F(1,46)=23.06, p<0.001, \eta^{2}=0.33$, along with a significant group $\times$ time interaction, $F(1,46)=32.79, p<0.001, \eta^{2}=0.42$
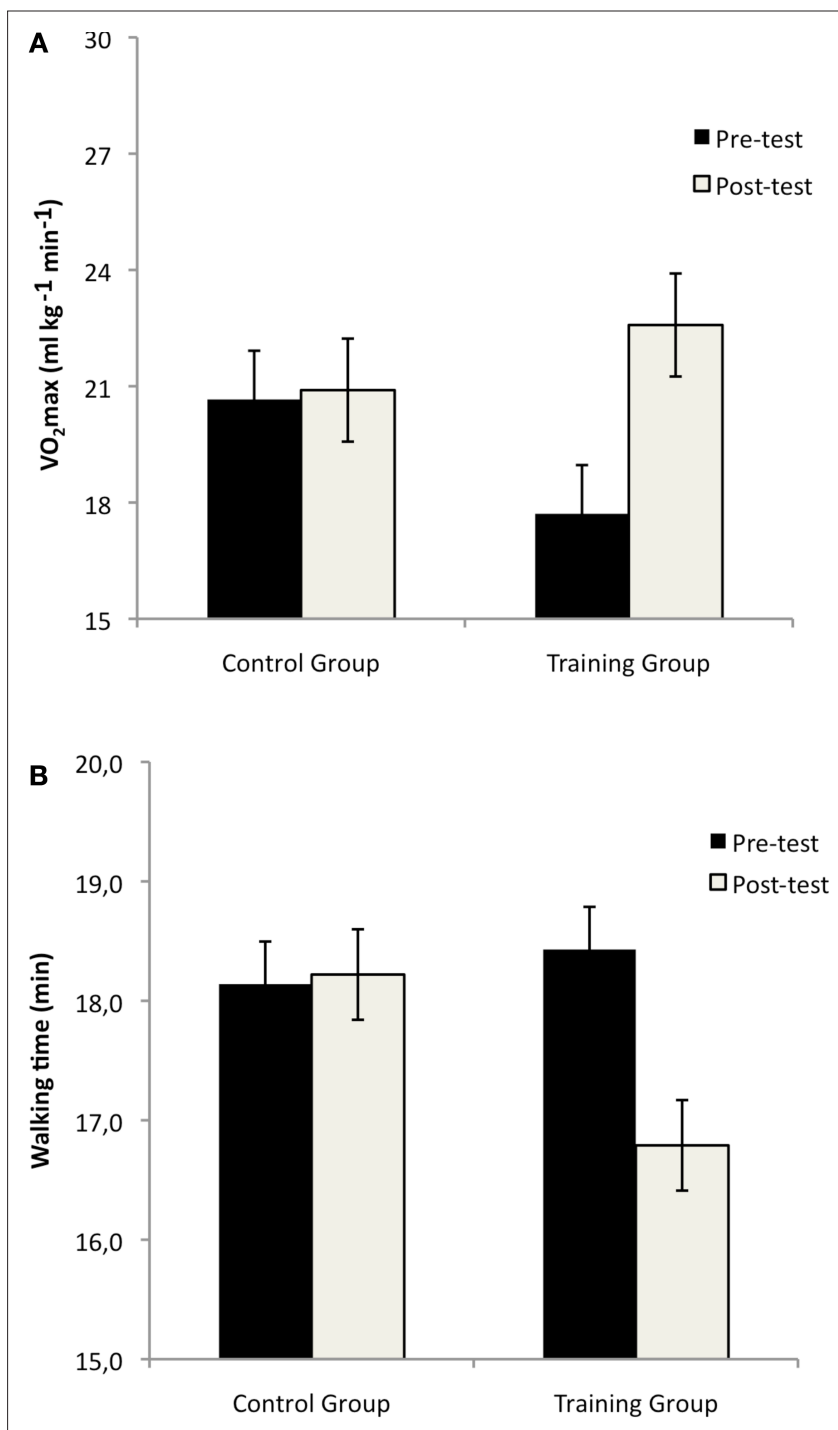

FIGURE 2 | Mean $\mathrm{VO}_{2}$ max estimate (A) and walking time (B) in the Rockport one-mile test at pre-test and post-test sessions, in the control and the training groups (Bars represent standard errors).

(see Figure 2B). Participants in the training group walked the mile faster after the 12-week training program, $F(1,24)=49.28$, $p<0.001, \eta^{2}=0.67$, whereas the walk time of participants in the control group did not change significantly, $F(1,24)<1$. It is important to emphasize that the aerobic training effects on the cardiorespiratory fitness assessment was equivalent in both the lower and the higher fit groups as indicated by the absence of a three-way interaction on $\mathrm{VO}_{2}$ max estimate, $F(1,46)=1.25$, ns, and walking time, $F(1,46)<1$.

\section{SIMPLE AND CHOICE RT TASKS}

The two variables of interest in the RT tasks were IT and ET. IT corresponds to the latency elapsed between the moment where the response signal (the black circle) appears on the screen and the moment at which the participant releases the home key. ET was measured from the moment the participant raises the index from 
the home key and presses the response key. Only RTs for correct responses were included in the analyses and trials were excluded from the analyses if IT was shorter than $100 \mathrm{~ms}$ or global RT was longer than $3000 \mathrm{~ms}$. Two types of errors can be produced in the RT tasks. Incorrect responses occur in the choice RT task and anticipation errors occur in both simple and choice RT tasks. In the choice RT task, participants produced virtually no incorrect responses. In fact, only two participants in the control group made one error at post-test. In general, participants made very few anticipation errors (leaving the home key before the response stimulus actually occurred). In the simple RT task, the mean number of anticipation errors at pre-test was 0.05 for the training group (lower fit: 0.06; higher fit: 0.04 ) and 0.04 for the control group (lower fit: 0.05 ; higher fit: 0.02 ). At post-test, the mean number of anticipation errors was 0.04 for the training group (lower fit: 0.06 ; higher fit: 0.02 ) and 0.09 for the control group (lower fit: 0.03 ; higher fit: 0.17$)$. The mean number of anticipation errors in the choice RT task was 0.03 for the training group (lower fit: 0.04 ; higher fit: 0.05 ) and 0.03 for the control group (lower fit: 0.04; higher fit: 0.02 ) at pre-test, and at post-test, 0.02 for the training group (lower fit: 0.02; higher fit: 0.02 ) and 0.07 for the control group (lower fit: 0.03; higher fit: 0.11 ). Anticipation errors were submitted to non-parametric tests (Kruskal-Wallis), which revealed that experimental groups produced a comparable number of anticipation errors and obtained similar anticipation scores in the simple RT task at pre-test, $\chi^{2}(3, N=50)=6.36$, ns, and post-test, $\chi^{2}(3$, $N=50)=7.46$, ns. Anticipation errors produced in the choice RT task were also equivalent among experimental groups at pre-test, $\chi^{2}(3, N=50)=3.65$, ns, and post-test, $\chi^{2}(3, N=50)=1.40$, ns.

\section{Training effects on task complexity}

Data were analyzed using an ANOVA with group (training and control) and baseline fitness level (lower fit and higher fit) as betweensubjects factors, and time (pre- and post-test) and task (simple and choice) as within-subjects factors.

The IT analysis revealed main effects of baseline fitness level, $F(1,46)=5.02, p<0.05, \eta^{2}=0.10$, time, $F(1,46)=5.45, p<0.05$, $\eta^{2}=0.11$, and task, $F(1,46)=159.54, p<0.001, \eta^{2}=0.78$. The baseline fitness level $\times$ time interaction also reached significance, $F(1,46)=8.78, p<0.01, \eta^{2}=0.16$, due to a larger improvement overall in the lower fit group, $F(1,24)=9.75, p<0.01, \eta^{2}=0.29$, compared to the higher fit group, $F(1,24)<1$. More importantly, the group $\times$ time interaction was significant, $F(1,46)=10.37, p<0.01$, $\eta^{2}=0.18$, and was qualified by a group $\times$ time $\times$ task interaction (depicted in Figure 3), $F(1,24)=7.91, p<0.01, \eta^{2}=0.15$, which suggests a differential improvement in performances between the training and the control group as a function of task complexity. Separate analyses performed for the simple and choice RT task revealed a significant group $\times$ time interaction in the choice RT task, $F(1,48)=12.10, p<0.001, \eta^{2}=0.20$, but not in the simple RT task, $F(1,48)=1.87$, ns. In the choice RT task, IT significantly improved from pre-test to post-test in the training group, $F(1,24)=13.11$, $p<0.001, \eta^{2}=0.36$, but remained unchanged in the control group, $F(1,24)=1.30$, ns.

The ET analysis revealed no effect of time or interaction involving this factor. A significant main effect of task was observed, $F(1,46)=80.63, p<0.001, \eta^{2}=0.64$, along with a group $\times$ base-

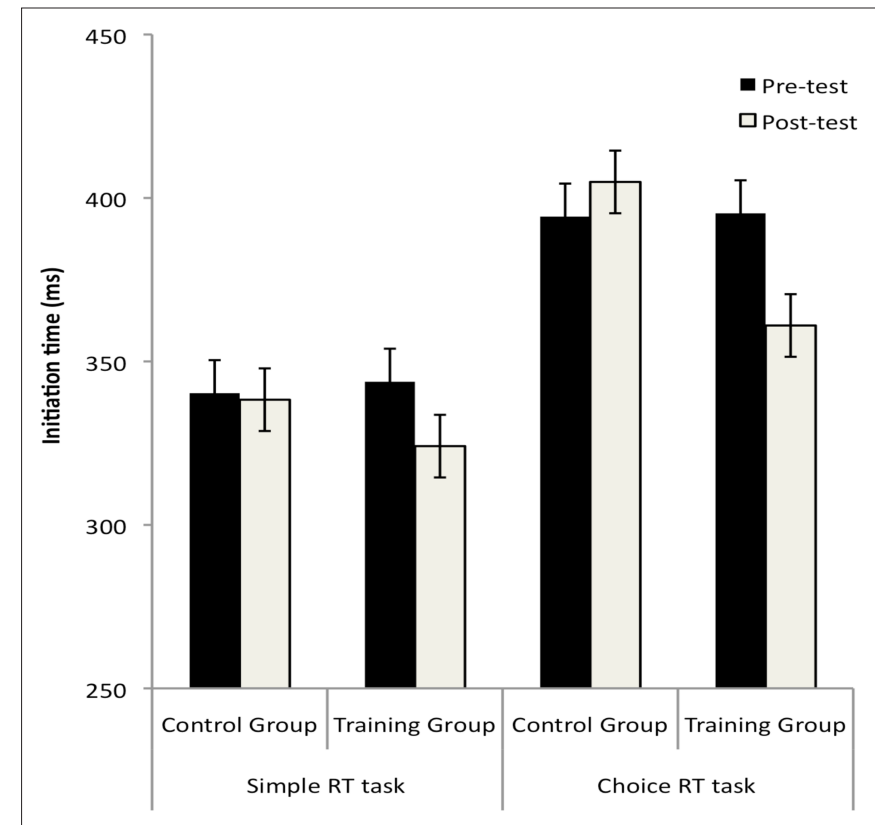

FIGURE 3 | Mean initiation time (ms) in the simple and the choice reaction time tasks in the control and the training groups (Bars represent standard errors).

line fitness level $\times$ task interaction, $F(1,46)=4.31, p<0.05$, $\eta^{2}=0.09$. To disambiguate this interaction, separate ANOVAs were carried out in each group separately. The baseline fitness level $\times$ task interaction was significant in the training group, $F(1$, $23)=5.00, p<0.05, \eta^{2}=0.18$, with a larger task effect in the lower fit group, $F(1,10)=18.96, p<0.001, \eta^{2}=0.66$, than in the higher fit group, $F(1,13)=18.23, p<0.001, \eta^{2}=0.58$. Respectively for the simple and the choice RT tasks, mean ET was 220 and $308 \mathrm{~ms}$ in the lower fit group and 202 and $244 \mathrm{~ms}$ in the higher fit group. In the control group, the baseline fitness level $\times$ task interaction did not reach significant level, $F(1,23)<1$, ns, (simple; $256 \mathrm{~ms}$, choice, $305 \mathrm{~ms}$ ).

\section{Training effects on response preparation}

Mean IT and standard deviation are presented in Table 2 (simple RT) and Table 3 (choice RT) as a function of duration condition and PI. Since training did not lead to significant improvement in the simple RT task (see results on the task complexity effect reported previously), the effects of the training intervention on response preparation are reported for the choice RT task only. Moreover, given that the PI effect (decrease in IT with increasing PI length) tends to be larger in short time windows than in long time windows (Niemi and Näätänen, 1981), training effects on response preparation were analyzed separately for each duration condition (short and long). The ANOVA involved group (control and training) and baseline fitness level (lower and higher) as between-subjects factors, and time (pre- and post-test) and PI (1st, 2nd, 3rd) as within-subject factors. Given that the PI effect involves more than two repeated levels, interactions involving this factor are reported significant according to the adjusted alpha-level (Huynh-Feldt corrections). 
Table 2 | Mean initiation time (in ms) and standard deviation (in parentheses) of the simple RT as a function of duration condition and PI.

\begin{tabular}{|c|c|c|c|c|c|c|}
\hline \multirow[b]{2}{*}{ Groups } & \multicolumn{3}{|c|}{ Short duration window } & \multicolumn{3}{|c|}{ Long duration window } \\
\hline & 1st PI & 2nd PI & 3rd PI & 1st PI & 2nd PI & 3rd PI \\
\hline \multicolumn{7}{|c|}{ TRAINING GROUP } \\
\hline \multicolumn{7}{|l|}{ Lower fit } \\
\hline Pre-test & $529.97(112.11)$ & $310.92(55.24)$ & $300.23(49.86)$ & 361.71 (68.25) & 330.59 (64.38) & $322.39(60.50)$ \\
\hline Pre-test & $411.82(91.71)$ & $293.57(39.05)$ & $283.97(33.82)$ & $340.18(62.53)$ & $323.20(62.12)$ & 317.31 (70.69) \\
\hline Post-test & $393.43(58.96)$ & 275.50 (35.92) & 271.42 (29.55) & $349.12(59.26)$ & $323.98(80.24)$ & $304.55(54.12)$ \\
\hline \multicolumn{7}{|c|}{ CONTROL GROUP } \\
\hline \multicolumn{7}{|l|}{ Lower fit } \\
\hline Pre-test & $460.92(119.66)$ & $311.13(60.37)$ & 301.61 (48.17) & 385.10 (51.98) & $348.62(64.81)$ & 340.27 (48 83) \\
\hline
\end{tabular}

Table 3 | Mean initiation time (in ms) and standard deviation (in parentheses) of the choice RT as a function of duration condition and PI.

\begin{tabular}{|c|c|c|c|c|c|c|}
\hline \multirow[b]{2}{*}{ Groups } & \multicolumn{3}{|c|}{ Short duration window } & \multicolumn{3}{|c|}{ Long duration window } \\
\hline & 1st PI & 2nd PI & 3rd PI & 1st PI & 2nd PI & 3rd PI \\
\hline \multicolumn{7}{|l|}{ Lower fit } \\
\hline Pre-test & 473.01 (86.66) & $390.23(87.87)$ & $393.11(93.01)$ & $463.84(74.72)$ & $422.40(73.44)$ & 418.55 (68 62) \\
\hline Pre-test & $403.76(72.72)$ & $337.13(49.15)$ & $333.01(54.32)$ & $389.14(48.48)$ & $364.86(51.30)$ & $354.68(48.30)$ \\
\hline Post-test & $384.06(56.45)$ & $329.00(40.53)$ & $318.64(44.27)$ & $371.24(64.66)$ & $354.28(56.40)$ & $340.93(52.41)$ \\
\hline \multicolumn{7}{|c|}{ CONTROL GROUP } \\
\hline \multicolumn{7}{|l|}{ Lower fit } \\
\hline Pre-test & 468.47 (76.89) & $381.48(57.59)$ & $375.05(59.72)$ & $440.88(54.87)$ & $431.57(52.30)$ & $404.74(56.77)$ \\
\hline
\end{tabular}

In the short duration condition of the choice RT task, the IT analysis indicated a significant main effect of PI, $F(1.6,71.74)=182.76$, $p<0.001, \eta^{2}=0.80$, a group $\times$ time interaction, $F(1,46)=15.14$, $p<0.001, \eta^{2}=0.25$, and a baseline fitness level $\times$ time interaction, $F(1,46)=11.04, p<0.01, \eta^{2}=0.19$. These interactions were qualified by a group $\times$ baseline fitness level $\times$ time $\times$ PI interaction (depicted in Figure 4), $F(2,92)=4.89, p=0.01, \eta^{2}=0.10$. This interaction suggests that changes in performances after the training program varied as a function of baseline fitness level and PI. Follow-up analyses were performed to assess the group $\times$ time interaction at each PI separately in the higher and the lower fit groups. In the higher fit group, a group $\times$ time interaction was observed at the 1 st, $F(1,23)=12.10$, $p<0.01, \eta^{2}=0.35,2$ nd, $F(1,23)=5.94, p<0.01, \eta^{2}=0.21$, and 3rd PI, $\left.F(1,23)=5.32, p<0.05, \eta^{2}=0.19\right)$, due to a longer IT at post-test than at pre-test in the control group [1st PI, $F(1,10)=12.94, p=0.01$, $\eta^{2}=0.56 ; 2$ nd PI, $F(1,10)=5.97, p<0.01, \eta^{2}=0.37$, and marginally significant at the 3rd PI; $\left.F(1,10)=4.43, p=0.06, \eta^{2}=0.31\right]$. IT did not change from pre-test to post-test in the training group $[F(1,13)<1$, ns for all PIs $]$.

Positive effects of training were observed in the lower fit group only, which showed a group $\times$ time interaction at the 2 nd PI, $F(1$, $23)=7.24, p<0.05, \eta^{2}=0.24$, and the 3rd PI, $F(1,23)=7.44$, $p<0.05, \eta^{2}=0.24$. The interaction was due to a significant improvement from pre-test to post-test in the training group at both PIs, [2nd PI; $F(1,10)=6.75, p<0.05, \eta^{2}=0.40$, 3rd PI; $\left.F(1,10)=8.36, p<0.05, \eta^{2}=0.46\right]$ which was not observed in the control group, [2nd PI; $F(1,13)<1$, 3rd PI; $F(1,13)<1$ ]. These results suggest that the aerobic training program lead to 

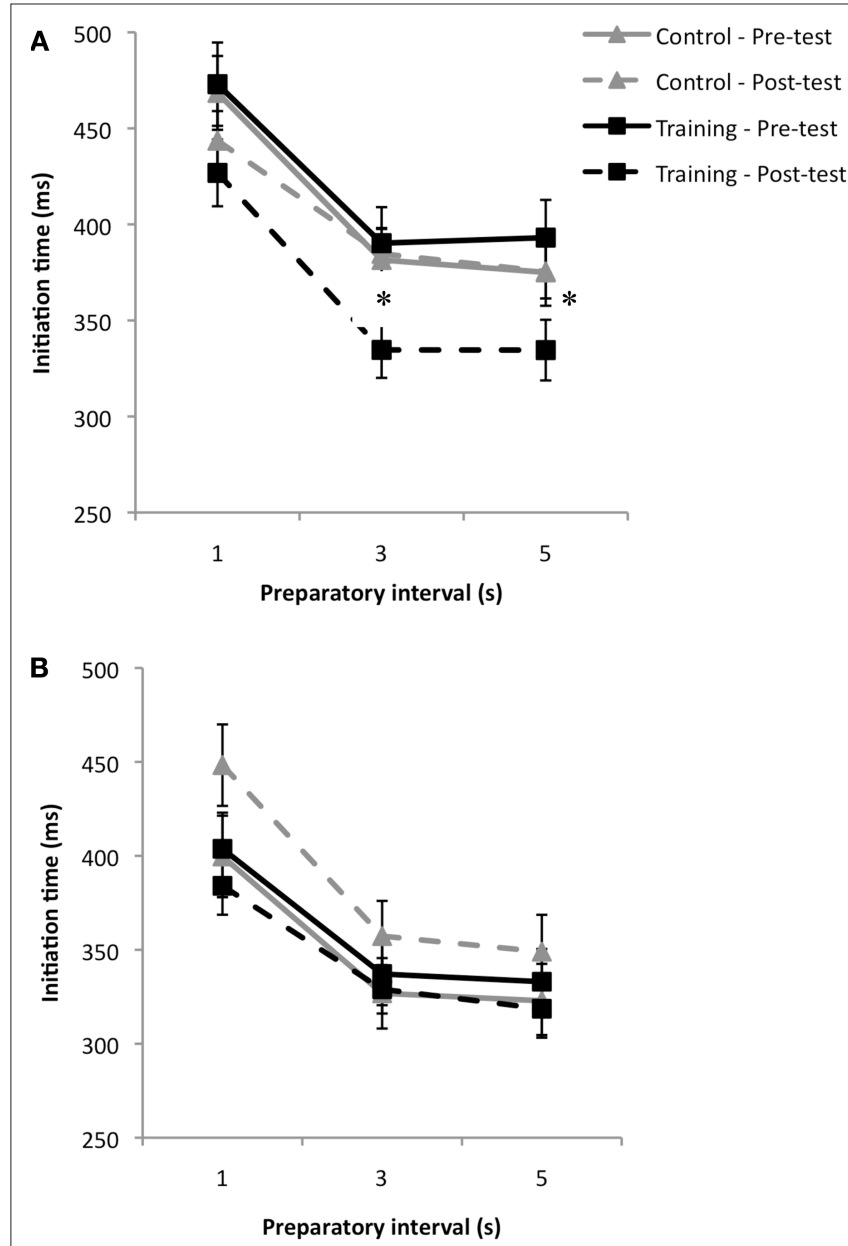

FIGURE 4 | Mean initiation time (ms) in the short temporal window of the choice RT task as a function of preparatory intervals at pre-test (solid line) and post-test (dashed line), in the lower fit (A) and the higher fit groups (B) (Bars represent standard errors).

significant improvement in the ability to prepare for the short PI in the lower fit group. The ET analysis did not show any main effects or interactions in the short temporal window of the choice RT task.

In the long duration condition, the IT analysis revealed a main effect of PI, $F(1.9,87.1)=39.92, p<0.001, \eta^{2}=0.47$, and a significant group $\times$ time interaction, $F(1,46)=8.78, p<0.05$, $\eta^{2}=0.16$, which was due to a significant improvement from pre-test to post-test in the training group, $F(1,24)=11.11$, $p<0.01, \eta^{2}=0.32$. IT did not change from pre-test to post-test in the control group, $F(1,24)<1$. These results suggest that the fitness training program lead to better ability to maintain preparation over time. There were no significant interactions involving the PI factor, suggesting that the improvement was equivalent at all PIs (see Figure 5). Moreover, the absence of any interaction involving the baseline fitness level suggests that the improvement observed in the long temporal window was equivalent among higher fit and lower fit individuals. Finally, the analysis on ET did not reveal any significant main effects or interactions.

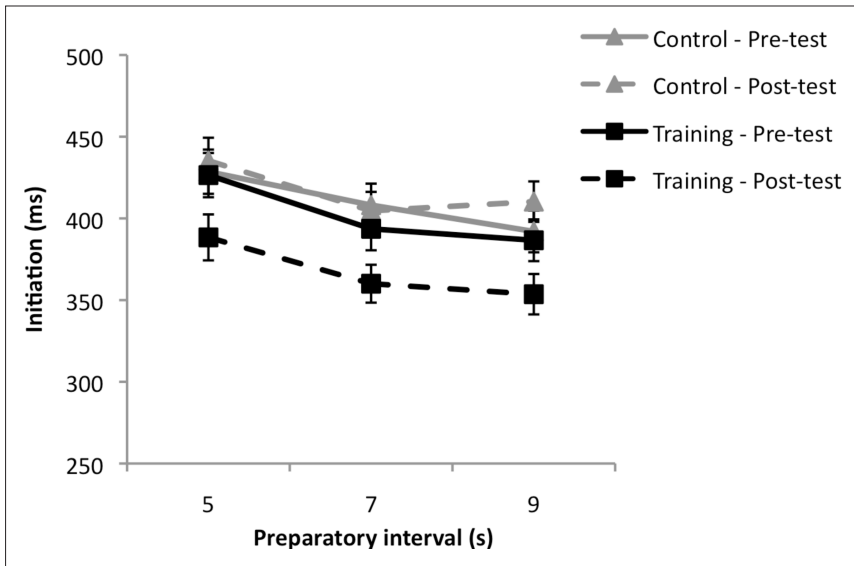

FIGURE 5 | Mean initiation time (ms) in the long temporal window of the choice RT task as a function of preparatory intervals at pre-test (solid line) and post-test (dashed line) (Bars represent standard errors).

\section{DISCUSSION}

The present study assessed the effect of a 3-month aerobic fitness training program on task complexity and response preparation in older adults, as a function of baseline fitness level, using simple and choice RT tasks designed to generate response preparation effects that have been associated to the integrity of the prefrontal cortex (see Vallesi et al., 2007).

Our results support the notion that sedentary elderly persons can benefit from a structured aerobic exercise program after only 3 months. The cardiorespiratory fitness level assessed with the Rockport one-mile test (Kline et al., 1987) indicated that 3 months of physical exercise lead to a $25 \%$ increase in physical fitness level. This suggests that even between 60 and 80 years of age, engaging in a physical fitness training program engenders strong benefits in cardiorespiratory function.

One goal of the present study was to assess the effect of aerobic fitness training in RT tasks while taking into account task complexity (simple vs. choice RT tasks). Past studies suggested that physical fitness should be associated to better performances in more complex tasks, because those tasks require controlled and effortful cognitive processing (Hall et al., 2001). The results reported in this study are consistent with this view. After the 3-month aerobic training program, improvement in initiation time was more important in the choice than in the simple RT task, thus suggesting that a speeded task that engages more cognitive processes would show greater improvement after training.

Another important question addressed in the present study was the effect of an aerobic training program on response preparation processes. Salthouse (1985) proposed two forms of inefficient preparation in normal aging: an incapacity to develop an optimal prepared state rapidly and an inability to maintain preparation over a certain period of time. Other studies have suggested that response preparation deficits could also be observed in older adults due to an inability to prepare for unlikely events (Bherer and Belleville, 2004a,b). The RT tasks used in the present study were designed to assess these three types of preparation deficits. In these tasks, a warning signal indicated to the participant to prepare for a speeded response to an upcoming stimulus, occurring after 
three PI of different durations. Within each temporal window, PIs varied randomly and could vary from 1,3 , or $5 \mathrm{~s}$ in the short duration window or from 5,7 , or $9 \mathrm{~s}$ in the long duration window. With such a variable PI paradigm, preparation depends upon the probability of stimulus occurrence, which increases with time after the warning signal has been presented. This produces a preparatory function according to which RT gets faster as PI duration increases within a given temporal window (Niemi and Näätänen, 1981).

The results observed in the present study suggest that an aerobic training intervention can lead to significant improvement in response preparation deficits in many ways, and that in some conditions, the improvement depends on the baseline fitness level of the participants. After controlling for age difference among higher and lower fit individuals, lower fit individuals that completed the aerobic training program showed better response preparation at the 2 nd and the 3 rd PI of the short temporal window of the choice RT task, suggesting enhanced ability to use stimulus probability. Moreover, all participants that completed the training program showed better performance in the long temporal window of the choice RT task, suggesting that they were better at maintaining a high level of preparation over time after the training program. The enhanced ability to maintain preparation over time was independent of the baseline fitness level.

These results bring further support to Hillman et al. (2002) findings that more active older and younger adults tend to show more efficient and less effortful response preparation than lower fit individuals in speeded RT tasks. In line with this finding, Renaud et al. (2010) used a cross-sectional design to compare the performances of lower and higher fit individuals in tasks that were similar to the one used in the present study. They observed that participants with higher levels of fitness responded faster at the shortest intervals of the short temporal window. Moreover, higher fit individuals were able to better maintain a higher level of preparation for a long period of time, up to $9 \mathrm{~s}$. The interpretation of these results was limited by the very nature of a cross-sectional design. Results of the present study bring additional support to these findings by showing that a 3-month exercise training program leads to significant improvement in response preparation. To our knowledge, it is the first intervention study to show that response preparation can be enhanced in older adults after an aerobic fitness training program.

One limitation of the present study is that the control group did not receive any form of intervention. One may argue that the effects of the intervention could be attributed to other factors than the aerobic intervention. For example, the training group was getting significantly more social interaction and this interaction could have contributed to improve cognition. However, other studies have

\section{REFERENCES}

Abourezk, T., and Toole, T. (1995). Effect of task complexity on the relationship between physical fitness and reaction time in older women. J. Aging Phys. Act. 3, 251-260.

Bherer, L., and Belleville, S. (2004a). Agerelated differences in response preparation: the role of time uncertainty. J. Gerontol. B Psychol. Sci. Soc. Sci. 59, P66-P74.

Bherer, L., and Belleville, S. (2004b). The effect of training on preparatory attention in older adults: evidence for the role of uncertainty in agerelated preparatory deficits. Aging Neuropsychol. Cogn. 11, 37-50.

Clarkson-Smith, L., and Hartley, A. A. (1989). Relationships between physical exercise and cognitive abilities in older adults. Psychol. Aging 4, 183-189.

Colcombe, S. J., Erickson, K. I., Scalf, P. E., Kim, J. S., Prakash, R., McAuley, E., Elavsky, S., Marquez, D. X., Hu, L., and Kramer, A. F. (2006). Aerobic exercise training increases brain volume in

controlled for this aspect and still found significant training effects. For instance, Kramer et al. (1999) assessed cognitive performances of sedentary older adults aged between 60 and 75 years old who were randomly assigned to an aerobic (walking) or a stretching and toning exercise group. They found that the participants who received aerobic training showed substantial improvement in attentional control tasks, which was not observed in the anaerobic group (for similar results see Dustman et al., 1984). These results suggest that social interaction may not be sufficient to improve cognitive performances in the context of exercise training intervention.

This study provides further support to the notion that cardiorespiratory fitness may offer a protective buffer against age-related cognitive decline. Evidence from neuroimaging studies could help to explain why executive control functions tend to benefit more readily from fitness training. It has been shown that enhanced cardiovascular functions after aerobic training are associated with greater taskrelevant activity in brain areas recruited in an attentional control task (Colcombe et al., 2004a,b, 2006). Thus, cardiorespiratory fitness has significant effects on brain regions that are strongly associated with the integrity of attentional control processes, such as those required in speeded response preparation tasks (Stuss et al., 1995).

Executive control functions are vital to the human autonomy, and although there is evidence for decline in these functions with advancing age, the results of the present study suggest that physical activity could be used as an intervention tool to attenuate this decline. The advantage of physical activity programs is that they can be relatively inexpensive, are accessible, and easy to begin at any age. Many everyday activities, such as driving, entail substantial executive controls demands. Indeed, the response preparation task using variable PIs design appears to reflect real-life demands as we often have to anticipate and prepare fast and accurate responses (e.g., at an intersection the yellow light warns the driver that a stop will soon be required). An important question for future research would be to see if the training benefits observed in experimental tasks as used in the present study transfer to everyday situations.

\section{ACKNOWLEDGMENTS}

This research was supported by a grant from the Institut universitaire de gériatrie de Montréal (CAREC program) and a scientist fellowship from the Fonds de Recherche en Santé du Québec to Louis Bherer. The authors wish to thank Guillaume Boussardon, Thierno Diallo, Laëtitia Haller, Delphine Middermacht, Martine Vézina, and Julie Brunet for their collaboration in the study as well as Charles H. Hillman for helpful comments on a previous version of this manuscript.

aging humans. J. Gerontol. A Biol. Sci. Med. Sci. 61, 1166-1170.

Colcombe, S. J., and Kramer, A. F. (2003). Fitness effects on the cognitive function of older adults: a meta-analytic study. Psychol. Sci. 14, 125-130.

Colcombe, S. J., Kramer, A. F., Erickson, K. I., Scalf, P., McAuley, E., Cohen, N. J., Webb, A., Jerome, G. J., Marquez, D. X., and Elavsky, S. (2004a). Cardiovascular fitness, cortical plasticity, and aging. Proc. Natl. Acad. Sci. U.S.A 101, 3316-3321.
Colcombe, S. J., Kramer, A. F., McAuley, E., Erickson, K. I., and Scalf, P. (2004b). Neurocognitive aging and cardiovascular fitness: recent findings and future directions. J. Mol. Neurosci. 24, 9-14.

Dustman, R. E., Ruhling, R. O., Russell, E. M., Shearer, D. E., Bonekat, H. W., Shigeoka, J. W., Wood, J. S., and Bradford, D. C. (1984). Aerobic exercise training and improved neuropsychological function of older individuals. Neurobiol. Aging 5, 35-42. 
Etnier, J. L., Nowell, P. M., Landers, D. M., and Sibley, B. A. (2006). A metaregression to examine the relationship between aerobic fitness and cognitive performance. Brain Res. Rev. 52, 119-130.

Folstein, M. F., Folstein, S. E., and McHugh, P. R. (1975). "Mini-mental state”. A practical method for grading the cognitive state of patients for the clinician. J. Psychiatr. Res. 12, 189-198.

Hall, C. D., Smith, A. L., and Keele, S. W. (2001). The impact of aerobic on cognitive function in older adults: a new synthesis based on the concept of executive control.Eur. J. Cogn. Psychol. 13, 279-300.

Hawkins, H. L., Kramer, A. F., and Capaldi, D. (1992). Aging, exercise, and attention. Psychol. Aging 7, 643-653.

Hertzog, C., Kramer, A. F., Wilson, R. S., and Lindenberger, U. (2009). Enrichment effects on adult cognitive development: can the functional capacity of older adults be preserved and enhanced? Psychol. Sci. Public Interest 9, 1-65.

Hillman, C. H., Weiss, E. P., Hagberg, J. M., and Hatfield, B. D. (2002). The relationship of age and cardiovascular fitness to cognitive and motor processes. Psychophysiology 39, 303-312.

Kline, G. M., Porcari, J. P., Hintermeister, R., Freedson, P. S., Ward, A., McCarron, R. F., Ross, J., and Rippe, J. M. (1987). Estimation of VO2max from a onemile track walk, gender, age, and body weight. Med. Sci. Sports Exerc. 19, 253-259.
Kramer, A. F., Bherer, L., Colcombe, S. J., Dong, W., and Greenough, W. T. (2004). Environmental influences on cognitive and brain plasticity during aging. J. Gerontol. A Biol. Sci. Med. Sci. 59, M940-M957.

Kramer, A. F., Hahn, S., Cohen, N. J., Banich, M. T., McAuley, E., Harrison, C. R., Chason, J., Vakil, E., Bardell, L., Boileau, R. A., and Colcombe, A. (1999). Ageing, fitness and neurocognitive function. Nature 400, 418-419.

McDowd, J. M., and Shaw, R. J. (2000). "Attention and aging: a functional perspective," in The Handbook of Aging and Cognition, eds F. I. M. Craik and T.A. Salthouse (New Jersey: Lawrence Erlbaum Associates), 221-292.

Nelson, M. E., Rejeski, W. J., Blair, S. N., Duncan, P. W., Judge, J. O., King, A. C., Macera, C.A., and Castaneda-Sceppa, C. (2007). Physical activity and public health in older adults: recommendation from the American College of Sports Medicine and the American Heart Association. Circulation 116, 1094-1105.

Niemi, P., and Näätänen, R. (1981). Foreperiod and simple reaction time. Psychol. Bull. 89, 133-162.

Raz, N. (2000). "Aging of the brain and its impact on cognitive performance: integration of structural and functional findings," in The Handbook of Aging and Cognition, eds F. I. M. Craik and T.A. Salthouse (New Jersey: Lawrence Erlbaum Associates), 1-90.

Renaud, M., Bherer, L., and Maquestiaux, F. (2010). A high level of physical fitness is associated with more efficient response preparation in older adults. J. Gerontol. Psychol. Sci. 65B, 317-322.

Rikli, R. E., and Edwards, D. J. (1991). Effects of a three-year exercise program on motor function and cognitive processing speed in older women. Res. Q. Exerc. Sport 62, 61-67.

Salthouse, T.A. (1985). "Speed of behavior and its implications for cognition," in Handbook of the Psychology of Aging, eds J.E. Birren and K. W. Schaie (New York: Van Nostrand Reinhold), 400-426.

Spirduso, W. W. (1975). Reaction and movement time as a function of age and physical activity level. J. Gerontol. 30, 435-440.

Stuss, D. T., Shallice, T., Alexander, M. P., and Picton, T. W. (1995). "A multidisciplinary approach to anterior attentional functions," in Structures and Functions of the Human Prefrontal Cortex, Vol. 769, eds J. Grafman, K. J. Holyoak, and F. Boller (New York: New York Academy of Sciences), 191-211.

Vallesi, A., Shallice, T., and Walsh, V. (2007). Role of the prefrontal cortex in the foreperiod effect: TMS evidence for dual mechanisms in temporal preparation. Cereb. Cortex, 17, 466-474.

Vuillemin, A., Oppert, J. M., Guillemin, F., Essermeant, L., Fontvieille, A. M., Galan, P., Kriska, A. M., and Hercberg, S. (2000). Self-administered questionnaire compared with interview to assess past-year physical activity. Med. Sci. Sports Exerc. 32, 1119-1124.

Wechsler, D. (1997). Wechsler Adult Intelligence Scale-Third Edition:
Administration and Scoring Manual. San Antonio, TX: The Psychological Corporation.

West, R. L. (1996). An application of prefrontal cortex function theory to cognitive aging. Psychol. Bull. 120, 272-292.

Yesavage, J. A., Brink, T. L., Rose, T. L., Lum, O., Huang, V., Adey, M., and Leirer, V. O. (1983). Development and validation of a geriatric depression screening scale: a preliminary report. J. Psychiatr. Res. 17, 37-49.

Conflict of Interest Statement: The authors declare that the research was conducted in the absence of any commercial or financial relationships that could be construed as a potential conflict of interest.

Received: 20 April 2010; paper pending published: 25 August 2010; accepted: 19 October 2010; published online: 11 November 2010.

Citation: Renaud M, Maquestiaux F, Joncas S, Kergoat M-J and Bherer L (2010) The effect of three months of aerobic training on response preparation in older adults. Front. Ag. Neurosci. 2:148. doi: 10.3389/ fnagi.2010.00148

Copyright ( $\odot 2010$ Renaud, Maquestiaux, Joncas, Kergoat and Bherer. This is an open-access article subject to an exclusive license agreement between the authors and the Frontiers Research Foundation, which permits unrestricted use, distribution, and reproduction in any medium, provided the original authors and source are credited. 